\title{
Isolasi dan Identifikasi Jamur Xerofilik pada Kopi Instant
}

\section{Isolation and Identification of Xerofilik Fungi on Instant Coffee}

\author{
Kartinah Wiryosoendjojo ${ }^{1)}$, Nony Puspawati ${ }^{2}$, Dewi Sulistyawati ${ }^{1^{*}}$ \\ ${ }^{1}$ Program Studi D-III Analis Kesehatan \\ ${ }^{2}$ Program Studi D-IV Analis Kesehatan \\ Fakultas Ilmu Kesehatan, Universitas Setia Budi \\ Jl. Letjen Sutoyo Mojosongo, Surakarta, Jawa Tengah 57121 \\ *Corresponding author: dewi.trop.08@gmail.com
}

Received: February 28, 2019; Revise: April 15, 2019; Accepted: May 3, 2019

DOI : https://doi.org/10.31001/biomedika.v12i1.411

\begin{abstract}
ABSTRAK
Proses produksi produk instan (termasuk kopi instan) apabila tidak dijaga dengan baik, bisa menyebabkan kontaminasi mikroba yang berbahaya bagi kesehatan. Kontaminasi mikrobia bisa menyebabkan diare, keracunan bahkan kematian. Beberapa kapang xerofilik dapat menghasilkan mikotoksin yang bisa menyebabkan keracunan. Pada penelitian ini akan diteliti apakah kopi instan yang dipasarkan di wilayah Sleman, Yogyakarta mengandung kapang xerofilik dan apa saja jenisnya. Penelitian ini termasuk penelitian observasional. Pengambilan sampel dilakukan secara random. Sampel kopi instan diambil di wilayah Sleman, Yogyakarta terdiri dari 5 kopi instan berbagai merk. Inokulasi dilakukan dengan tehnik taburan pada media DG 18 (Dichloran 18\% Gliserol). Hasil penelitian ini membuktikan kopi instant di daerah Sleman, Yogyakarta mengandung spora jamur xerofilik. Jenis kapang xerofilik yang terdapat pada kopi instant di daerah Sleman, Yogyakarta adalah Fusarium culmorum, Aspergillus niger, Curvularia lunata, Cladosporium macrocarpum, Geotrichum candidum.
\end{abstract}

Kata kunci : jamur; xerofilik; kopi instan

\section{ABSTRACT}

The process of producing instant products (including instant coffee) if not properly maintained, can cause microbial contamination which is harmful to health. Microbial contamination can cause diarrhea, poisoning and even death. Some xerophilic molds can produce mycotoxins which can cause poisoning. In this research, it will be investigated whether instant coffee which is marketed in Sleman, Yogyakarta contains xerophilic molds and what are the types. This research is an observational research. Sampling is done randomly. Instant coffee samples taken in the area of Sleman, Yogyakarta consists of 5 instant coffee of various brands. The inoculation was carried out with a sprinkling technique on DG 18 media (Dichloran 18\% Glycerol). The results of this study prove that instant coffee in Sleman, Yogyakarta contains xerophilic mushroom spores. The types of xerophilic molds found in instant coffee in Sleman, Yogyakarta are Fusarium culmorum, Aspergillus niger, Curvularia lunata, Cladosporium macrocarpum, Geotrichum candidum.

Keywords: fungi; xerophilic; instant coffee

"Jurnal Biomedika" is an open access article under the CC BY-SA license

https://creativecommons.org/licenses/by-sa/4.0/ 


\section{PENDAHULUAN}

Masyarakat zaman sekarang membutuhkan proses penyediaan makanan dan atau minuman yang cepat, praktis, dan rasa (taste) yang memenuhi selera. Kebutuhan tersebut "dijawab" dengan adanya produk yang serba instant, misalnya kopi instant, jahe instant, mie instant, dsb. Proses pembuatan produk untuk keperluan instant ini membutuhkan cara produksi yang lebih rumit, ruang penyimpanan yang bersih, dan packing yang bagus (Noveriza, 2008).

Proses produksi produk instan (termasuk kopi instan) apabila tidak dijaga dengan baik, bisa menyebabkan kontaminasi mikroba yang berbahaya bagi kesehatan. Kontaminasi mikrobia bisa menyebabkan diare, keracunan bahkan kematian. Pengujian secara mikrobiologis (bakteriologis maupun mikologis) perlu dilakukan untuk mencegah kejadian yang tidak diinginkan. Beberapa kapang xerofilik dapat menghasilkan mikotoksin yang bisa menyebabkan keracunan. Pada penelitian ini akan diteliti apakah kopi instan yang dipasarkan di wilayah Sleman, Yogyakarta mengandung kapang xerofilik dan apa saja jenisnya.

Hasil penelitian ini diharapkan bisa memberikan informasi bagi masyarakat untuk lebih hati-hati dan teliti dalam mengkonsumsi kopi instan dan bagi para produsen kopi instan agar lebih memperhatikan higienitas dalam proses produksi. Luaran yang akan dihasilkan berupa jurnal penelitian.

Spora jamur xerofilik mampu bertahan hidup pada kondisi kering (Rahayu, 2007). Jamur xerofilik mampu tumbuh baik pada medium Dichloran $18 \%$
Glycerol Agar (DG 18). Medium DG 18 mendukung pertumbuhan jamur xerofilik seperti Eurotium, Aspergillus, Penicillium, Wallemia, Saccharomyces, dan Debaryomyces. Medium ini mengandung gliserol, yang bermanfaat sebagai sumber karbon bagi jamur, dan menyebabkan kadar air medium menjadi 18\% (Pitt \& Hocking, 2009).

Adanya kontaminan jamur xerofilik dalam suatu produk dapat membahayakan konsumen, karena beberapa species jamur xerofilik dapat menghasilkan mikotoksin. Mikotoksin dapat menyebabkan terjadinya mikotoksikosis (Sukmawati, et al. 2018). Produksi mikotoksin ditunjang oleh kondisi optimum,seperti kadar air 18 $30 \%$, suhu $30-40^{\circ} \mathrm{C}$, dan $\mathrm{Rh} 85 \%$ (Rukmini, 2009).

Jamur xerofolik menghasilkan mikotoksin. Penghasil mikotoksin terutama berasal dari genus Aspergillus, Penicillium, dan Fusarium. Seseorang yang mengkonsumsi produk yang tercemar mikotoksin secara terus menerus dapat mengakibatkan penurunan kualitas kesehatan. Manifestasi penurunan kualitas kesehatan dapat berupa penurunan daya tahan tubuh, pertumbuhan yang lambat pada anak-anak, kerusakan organ hati, bahkan kematian (Rahayu, 2007).

Berdasarkan atas latar belakang tersebut di atas, permasalahan penelitian adalah melakukan isolasi jamur xerofilik dari produk kopi instant. Sampel yang digunakan adalah kopi instant yang didapat dariwilayah Sleman, Yogyakarta. Penelitian ini bertujuan untuk mengetahui adanya jenis-jenis jamur xerofilik pada kopi instant di wilayah Sleman, Yogyakarta. 


\section{METODE PENELITIAN}

\section{Alat dan Bahan}

Otoklaf, entkas, gunting, api spirtus, jarum Ose, spuit steril, tabung reaksi, , mikroskop binokuler. Bahan yang digunakan untuk penelitian ini adalah medium DG 18, akuades steril, Lactophenol Cotton Blue.

\section{Sampel}

Sampel yang digunakan dalam penelitian ini adalah 5 jenis sampel kopi instan yang beredar di wilayah Sleman, Yogyakarta.

\section{Prosedur Penelitian}

a. Persiapan suspensi dan pengenceran sampel

Masing masing sampel kopi instan diambil 1 gram dan dilarutkan dalam 9 ml aquadest tingkat pengenceran $10^{-1}$. Setelah itu, dilakukan pengenceran secara bertingkat sehingga diperoleh pengenceran pada tingkat $10^{-2}, 10^{-3}, 10^{-4}$.

b. Inokulasi dan Inkubasi Sampel

Suspensi sampel masing-masing pengenceran diinokulasikan sebanyak $0,1 \mathrm{ml}$ pada medium DG 18 , kemudian diinkubasi pada suhu $25^{\circ} \mathrm{C}$ selama 3-5 hari.

c. Pembuatan Preparat dan Identifikasi Jamur xerofilik

Identifikasi jamur xerofilik dilakukan dengan membuat preparat jamur menggunakan metode Slide culture. Setelah itu dilakukan pengamatan ciri mikroskopis. Hasil pengamatan dirujukkan pada buku kunci identifikasi fungi yaitu "Introduction to FoodBorn Fungi" (Samson, 1984) dan "Fungi and Food Spoilage" (Pitt dan Hocking, 1985), untuk menentukan nama spesies jamur xerofilik yang ditemukan pada sampel kopi instan.

\section{HASIL DAN PEMBAHASAN}

\section{Pengamatan Makroskopik}

Pemeriksaan sampel 1 ditunjukkan pada Gambar 1 dan Tabel 1.

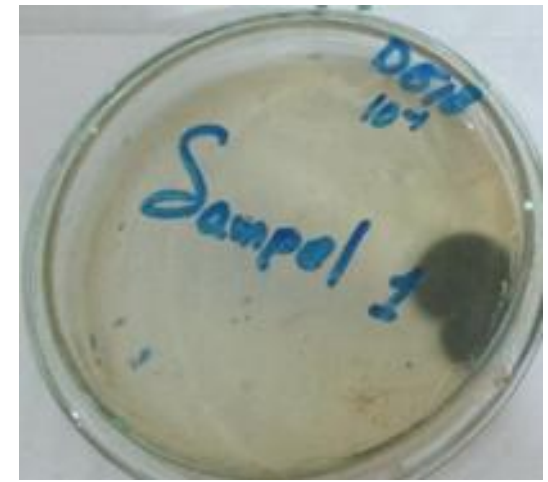

A

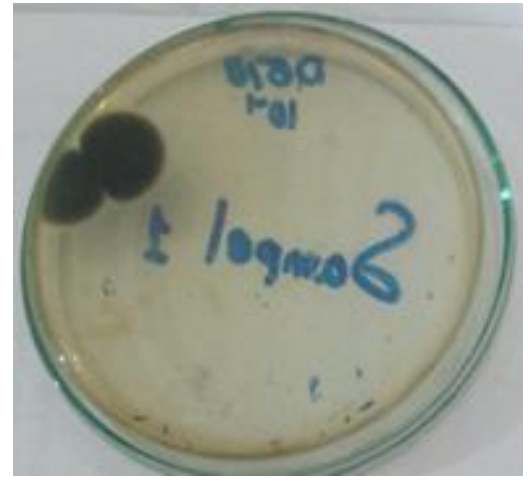

B

Gambar 1. (A) Tampak atas, (B) Tampak bawah 
Tabel 1. Hasil pengamatan jamur xerofilik

\begin{tabular}{ccccc}
\hline No. & Bentuk Koloni & $\begin{array}{c}\text { Warna permukaan } \\
\text { atas }\end{array}$ & $\begin{array}{c}\text { Warna permukaan } \\
\text { bawah }\end{array}$ & Jenis \\
\hline 1. & Beludru & hitam kehijauan & Hitam & Cladosporium \\
& & & macrocarpum \\
\hline
\end{tabular}

Pemeriksaan sampel 2 ditunjukkan pada Gambar 2 dan Tabel 2.

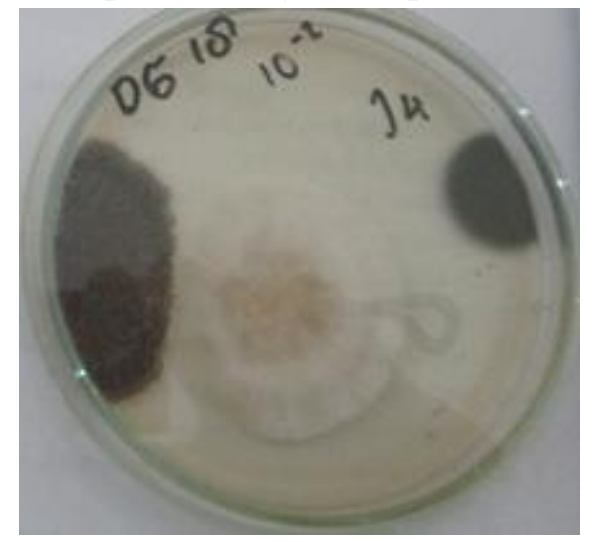

A

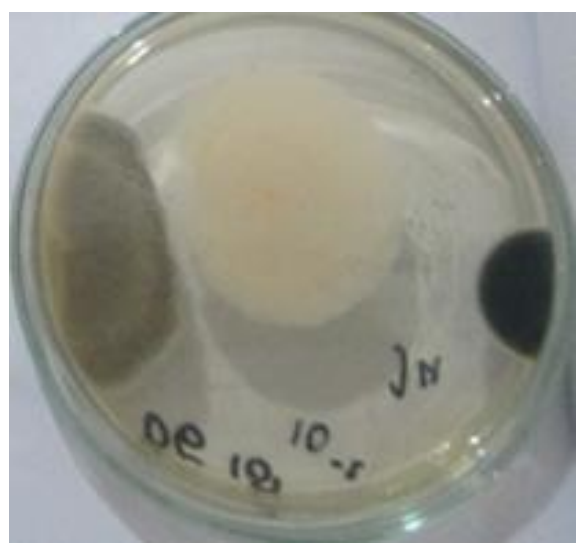

B

Gambar 2. (A) Tampak atas,

(B) Tampak bawah

Tabel 2. Hasil pengamatan jamur xerofilik

\begin{tabular}{ccccc} 
No. & Bentuk Koloni & $\begin{array}{c}\text { Warna permukaan } \\
\text { atas }\end{array}$ & $\begin{array}{c}\text { Warna permukaan } \\
\text { bawah }\end{array}$ & Jenis \\
\hline 1. & Pasir & Hitam & putih kekuningan & Aspergillus niger \\
\hline 2. & beludru & hitam kehijauan & Hitam & Cladosporium \\
& & & macrocarpum \\
\hline 3. & kapas & Putih & oranye muda & Fusarium culmorum
\end{tabular}

Pemeriksaan sampel 3 ditunjukkan pada Gambar 3 dan Tabel 3.

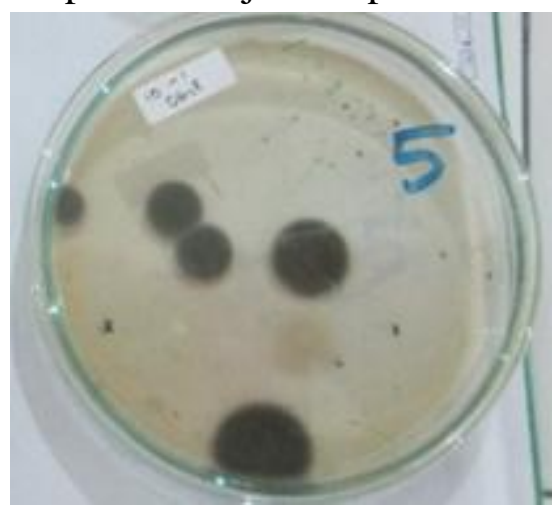

A

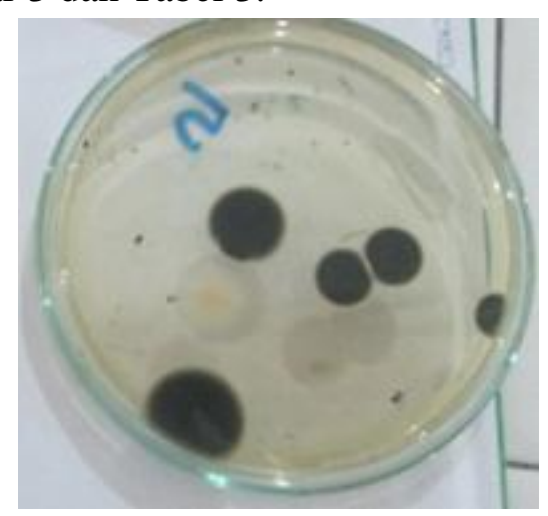

B

Gambar 3. (A) Tampak atas, (B) Tampak bawah 
Tabel 3. Hasil pengamatan jamur xerofilik sampel 3

\begin{tabular}{ccccc}
\hline No & Bentuk koloni & $\begin{array}{c}\text { Warna permukaan } \\
\text { atas }\end{array}$ & $\begin{array}{c}\text { Warna permukaan } \\
\text { bawah }\end{array}$ & Jenis \\
\hline 1. & Beludru, datar & putih & putih & Geotrichum candidum \\
\hline 2. & beludru & hitam kehijauan & hitam & Cladosporium \\
& & & macrocarpum \\
\hline
\end{tabular}

Pemeriksaan sampel 4 ditunjukkan pada Gambar 4 dan Tabel 4.

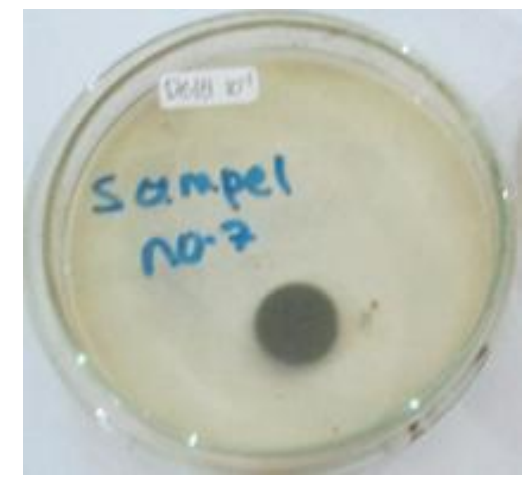

A

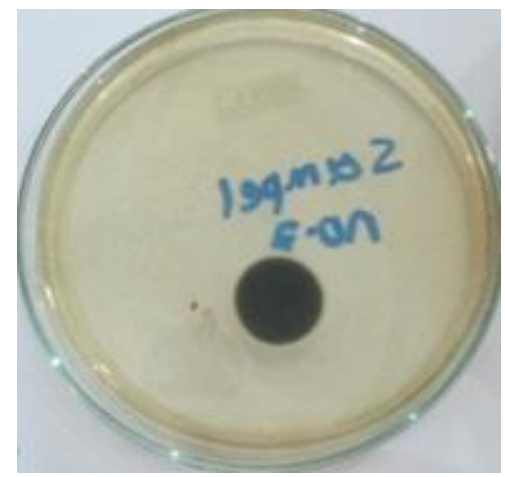

B

Gambar 4. (A) Tampak atas, (B) Tampak bawah

Tabel 4. Hasil pengamatan jamur xerofilik sampel 4

\begin{tabular}{lcccc}
\hline No. & Bentuk Koloni & $\begin{array}{c}\text { Warna permukaan } \\
\text { atas }\end{array}$ & $\begin{array}{c}\text { Warna permukaan } \\
\text { bawah }\end{array}$ & Jenis \\
\hline 1. & Beludru & hitam kehijauan & hitam & Cladosporium macrocarpum \\
\hline
\end{tabular}

Pemeriksaan sampel 4 ditunjukkan pada Gambar 4 dan Tabel 4.

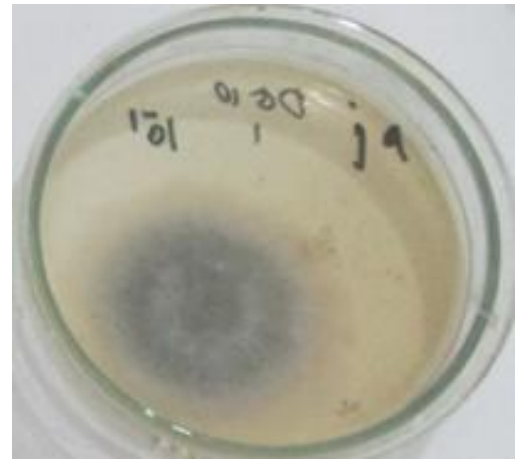

A

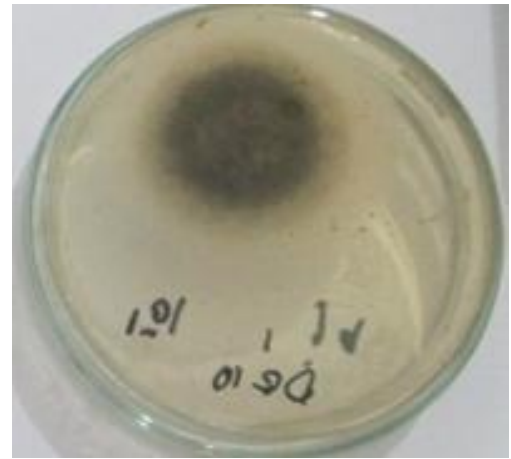

B

Gambar 5. (A) Tampak atas, (B) Tampak bawah 
Tabel 5. Hasil pengamatan jamur xerofilik sampel 5

\begin{tabular}{lcccc} 
No. Bentuk Koloni & $\begin{array}{c}\text { Warna permukaan } \\
\text { atas }\end{array}$ & $\begin{array}{c}\text { Warna permukaan } \\
\text { bawah }\end{array}$ & Jenis \\
\hline 1. & kapas & hitam keabuan & Hitam & Curvularia lunata
\end{tabular}

\section{Pengamatan Mikroskopik :}

\section{Fusarium culmorum}

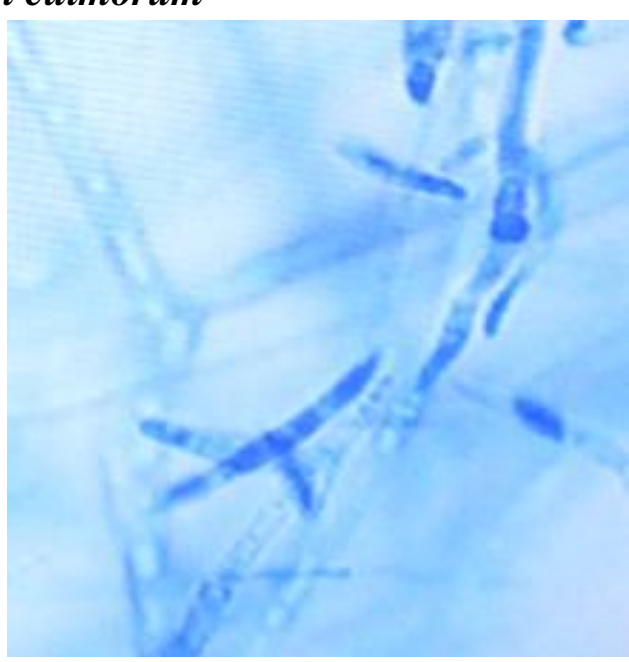

A

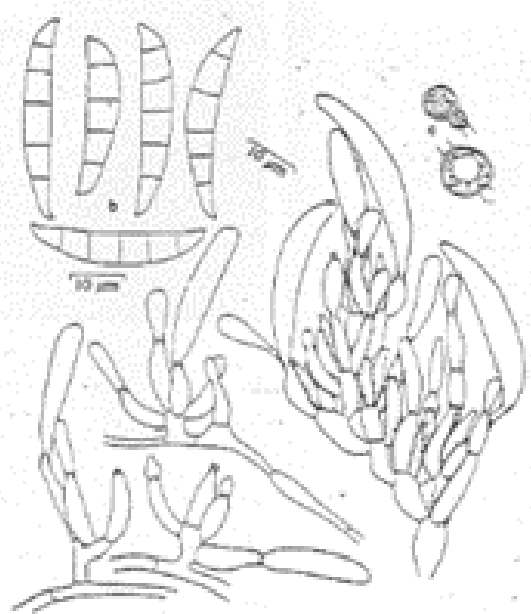

B

Gambar 6. (A) Mikroskopik Fusarium culmorum (perbesaran 400x),

(B) struktur Fusarium culmorum (Sumber: Samson dkk, 1984, halaman 82, 83).

\section{Cladosporium macrocarpum}

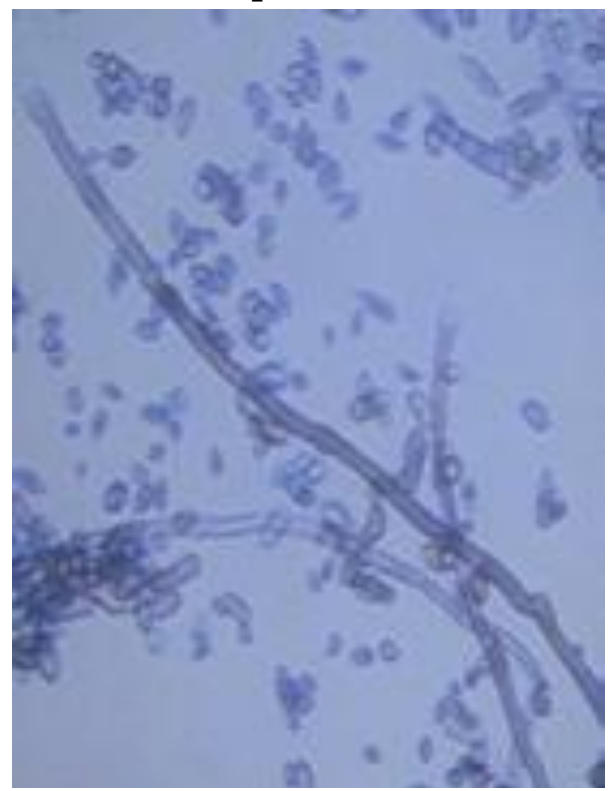

A

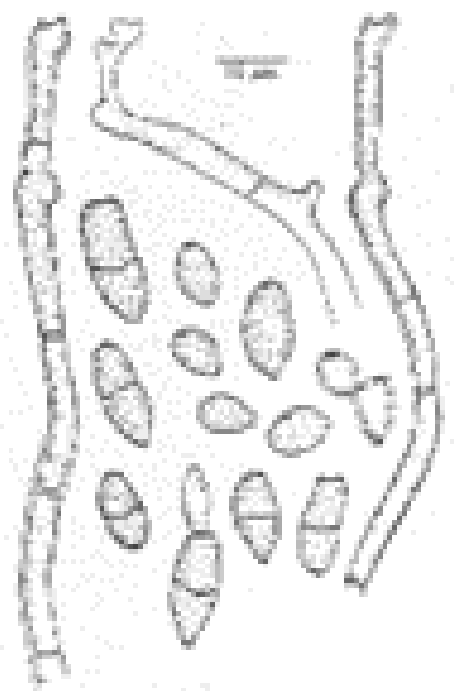

B

Gambar 7. (A) Mikroskopik Cladosporium macrocarpum (perbesaran 400x),

(B) struktur Cladosporium macrocarpum (Sumber : Samson et al, 1984, halaman 180) 


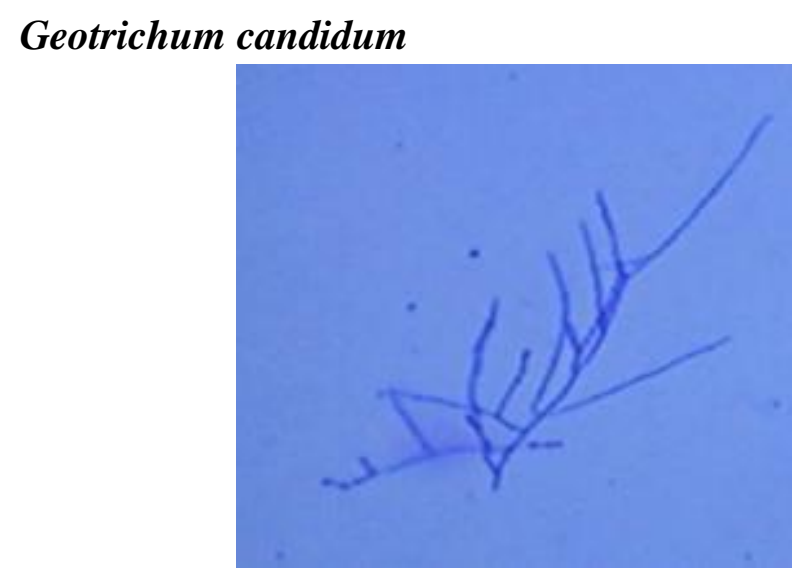

A

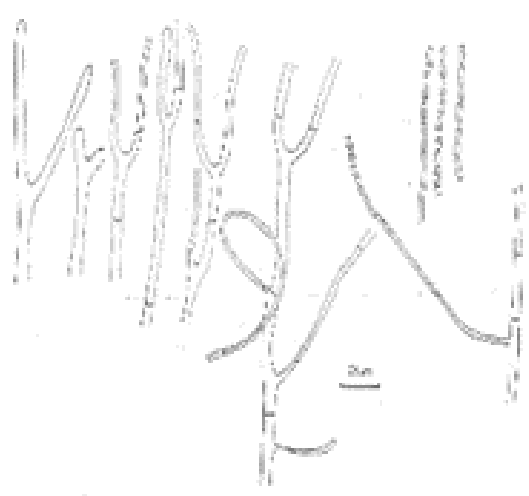

B

Gambar 8. (A) Mikroskopik Geotrichum candidum (perbesaran 400x),

(B) struktur Geotrichum candidum (Sumber : Samson et al, 1984, halaman 170)

\section{Curvularia lunata}

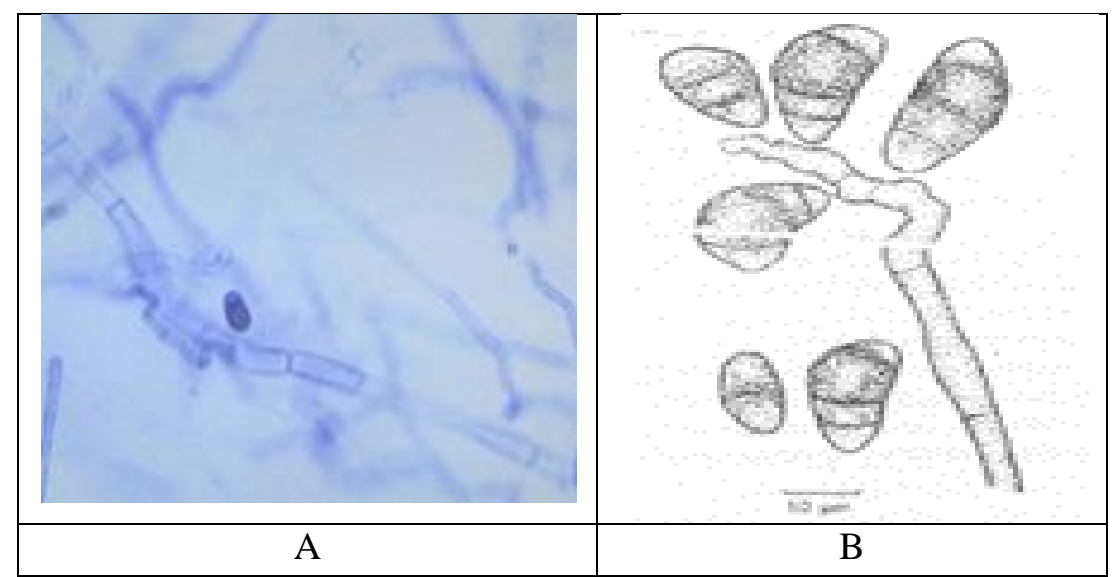

Gambar 9. (A) Mikroskopik Curvularia lunata (perbesaran 400x),

(B) struktur Curvularia lunata (Sumber : Pitt et al, 1985, halaman 93)

\section{Aspergillus niger}

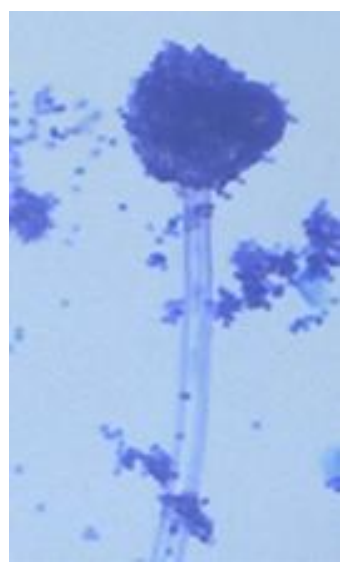

A
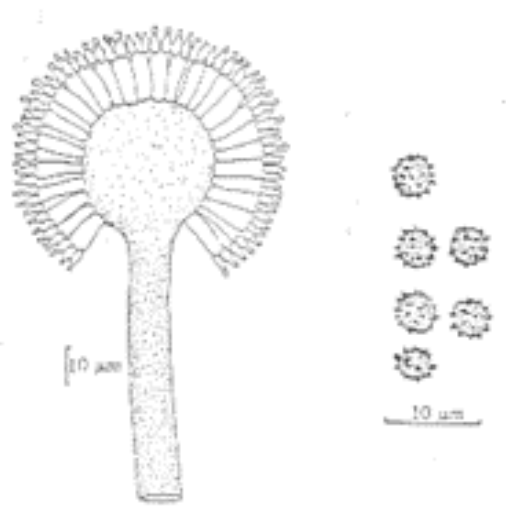

$\mathrm{B}$

Gambar 10. (A) Mikroskopik Aspergillus niger (perbesaran 400x),

(B) struktur Aspergillus niger (Sumber : Samson et al, 1984, halaman 174). 
Hasil penelitian pada 5 sampel kopi instan, ditemukan 5 jenis jamur xerofilik (gambar 6,7,8,9 dan 10). Ciri-ciri kelima jenis jamur xerofilik tersebut adalah sebagai berikut :

\section{Fusarium culmorum}

Makrokonidia pendek, terdiri dari 3-5 septa. Konidiofor umumnya bercabang pendek, dinding konidia agak tebal. Makrokonidia umumnya mempunyai 5 septa (kadang-kadang septa 3-4, atau 6-8). Mikrokonidia tidak ada. Klamidospora berwarna kecoklatan,dinding halus atau kasar, membentuk untaian seperti rantai, atau tunggal, atau tidak ada (Samson et al, 1984).

\section{Cladosporium macrocarpum}

Koloni dengan permukaan atas hitam kehijauan, permukaan bawah hitam kehijauan. Konidia kadang-kadang membentuk rangkaian pendek, septa $0-3$, elips (Pitt \& Hocking, 1985). Koloni mirip dengan Cladosporium herbarum. Cabang konidiofor lebih sedikit dibandingkan Cladosporium herbarum. Konidia elips, atau silindris pendek, ujung membulat, bersepta atau tidak, septa ke tiga umumnya membesar, coklat, permukaan kasar. Species ini sering ditemukan pada berbagai produk pangan, dan pernah diisolasi dari barley (Pitt \& Hocking, 1985). Jamur ini dapat diisolasi dari tanah, biji-bijian, bulu-bulu burung yang hidup bebas (Miskiyah, et al. 2015; Wange et al. 2019).

\section{Geotrichum candidum}

Koloni berwarna putih. Karakteristik jamur Geotrichum candidum adalah adanya hifa bersepta, ujung bercabang dikotom. Konidia berasal dari pecahnya hifa, membentuk rantai (Samson et al, 1984).

\section{Curvularia lunata}

Konidia Curvularia berbentuk elips dan panjang. Umumnya Curvularia patogen pada tanaman, kecuali Curvularia lunata. Species ini dapat dapat mengkontaminasi makanan, dan mempunyai askospora.

\section{Aspergillus niger}

Karakteristik A. niger adalah mempunyai konidia berwarna hitam, sehingga koloni selalu berwarna hitam. Vesikula besar, bulat (Samson et al, 1984). Hasil penelitian terhadap 5 sampel kopi instan yang di dapat di wilayah Sleman, Yogyakarta yang diisolasi pada medium DG 18 menunjukkan bahwa sampel kopi instan mengandung spora kapang yang masih intak. Spora jamur kontaminan dapat berasal dari udara, dari peralatan atau dari bahan tambahan produk. Spora tersebut mampu tumbuh dengan baik pada medium dengan kadar air yang rendah, yaitu medium DG 18, membentuk koloni dengan warna dan struktur mikroskopik yang spesifik.

Kemampuan spora jamur bertahan hidup dalam produk disebabkan karena jamur mempunyai struktur dinding spora tebal, misalnya pada Aspergillus niger, Curvularia lunata, Fusarium culmorum, Cladosporium macrocarpum, adanya klamidospora, misalnya pada Fusarium culmorum, jamur mampu membentuk artrospora, misalnya jamur Geotrichum candidum.

Pada sampel 1 ditemukan jenis kapang yaitu Cladosporium macrocarpum, pada sampel 2 ditemukan 3 jenis kapang 
yaitu Aspergillus niger, Cladosporium macrocarpum dan Fusarium culmorum, pada sampel sampel 3 ditemukan 2 jenis kapang Geotrichum candidum dan Cladosporium macrocarpum, pada sampel 4 ditemukan 1 jenis kapang yaitu Curvularia lunata dan pada sampel 5 ditemukan 1 jenis kapang yaitu Curvularia lunata.

Jamur yang berpotensi menghasilkan toksin adalah Aspergillus niger, menghasilkan ochratoksin A (Rukmini, 2009); Fusarium culmorum menghasilkan toksin zearalenon (Gupta, 2007); Curvularia lunata menghasilkan toksin methyl 5 - (hydroxymethyl)furan 2 - carboxylate(Liu et al 2010). Sifat masing-masing jamur yang ditemukan, yaitu Fusarium culmorum, mampu membentuk klamidospora. Jamur ini tumbuh optimum pada suhu $25^{\circ} \mathrm{C}, \mathrm{a}_{\mathrm{w}}$ minimum mendekati 0,9. Koloni jamur ini mempunyai miselium aerial berwarna putih, permukaan bawah kemerahan sampai ungu atau coklat. Fusarium culmorum patogen pada tanaman, terutama di daerah sub tropis, menyebabkan pembusukan biji dan akar. Jamur ini dilaporkan banyak mengkontaminasi kentang, kacang-kacangan, dan berbagai biji-bijian seperti oat, barley, tepung terigu (Pitt \& Hocking, 1985). Jamur ini menyebabkan busuk pada apel, kentang, beet yang disimpan di lemari pendingin. Ekstrak jamur ini menyebabkan kematian pada kelinci (Samson et al, 1984).

\section{Cladosporum}

macrocarpum,

koloni sangat mirip dengan Cladosporium herbarum. Cabang konidiofor lebih sedikit dibandingkan Cladosporium herbarum. Konidia elips, atau silindris pendek, ujung membulat, bersepta atau tidak, septa ke tiga umumnya membesar, coklat, permukaan kasar. Species ini sering ditemukan pada berbagai produk pangan, dan pernah diisolasi dari barley (Pitt \& Hocking, 1985). Jamur ini dapat diisolasi dari tanah, biji-bijian, bulu-bulu burung yang hidup bebas (Samson et al, 1984).

Jamur Geotrichum candidum mempunyai tanda karakteristik mempunyai arthroconidia yang berada pada hifa vegetatif. Koloni terdiri dari miselium, berwarna putih, permukaan bawah pucat. Konidia tumbuh lambat, tahan terhadap suhu $52^{\circ} \mathrm{C}$ selama 30 menit. Jamur Geotrichum candidum menyebabkan pembusukan pada buah Citrus, anggur, dan buah-buahan lainnya. Jamur ini tumbuh lambat pada suhu $10^{\circ} \mathrm{C}$. Jamur ini juga mengkontaminasi buah yang dikalengkan, susu pasteurisasi, berbagai produk pangan seperti daging, keju, dan produk pangan yang didinginkan dalam refrigerator (Pitt \& Hocking, 1985). Jamur ini tersebar luas di alam, di tanah, udara, jagung, tekstil, Citrus, pisang, tomat, mentimun, susu dan olahannya, hewan, dan manusia (Mizana, et. al., 2016).

Curvularia lunata pada medium Malt Ekstrak Agar (MEA) diameter koloni dapat mencapai $6 \mathrm{~cm}$, dan menghasilkan banyak konidia. Permukaan atas berwarna abu-abu sampai keputihan, permukaan bawah umumnya berwarna abu-abu sampai hitam. Karakteristik konidia terdiri sampai 4 sel, sel ke tiga asimetris, berwarna coklat muda, bagian medial lebih gelap. Kapang ini umumnya ditemukan pada cereal, termasuk beras, barley, terigu, jagung dan sorghum, buah leci, dan kacang-kacangan (Pitt \& Hocking, 1985; Santika et al., 2017)).

Jamur Aspergillus niger mampu tumbuh pada $\mathrm{pH}$ 2,0. Jamur ini hampir 
selalu ditemukan pada berbagai produk pangan, terutama pada cuaca yang hangat. A. niger menyebabkan kerusakan pada berbagai jenis buah seperti pear, apel, anggur, strawberries, tomat, dan juga pada selai. Jamur ini mampu tumbuh sebagai kontaminan hampir pada semua produk (Samson et al, 1984). A. niger tahan terhadap cahaya matahari. Jamur ini seringkali mengkontaminasi produk yang dikeringkan dengan cahaya matahari, seperti ikan kering. Produk daging yang diawetkan dengan pengeringan juga terkontaminasi oleh jamur ini (Pitt \& Hocking, 1985).

\section{KESIMPULAN}

Kopi instant di daerah Sleman, Yogyakarta terdapat spora jamur xerofilik. Jenis kapang xerofilik yang terdapat pada kopi instant di daerah Sleman, Yogyakarta adalah Fusarium culmorum, Aspergillus niger, Curvularia lunata, Cladosporium macrocarpum, Geotrichum candidum.

\section{UCAPAN TERIMA KASIH}

Ucapan terimakasih disampaikan kepada Yayasan Setia Budi Universitas Setia Budi yang telah memberikan kesempatan sehingga penelitian ini dapat berjalan dengan lancar. Selain itu kami ucapkan terima kasih banyak pada staf laboratorium Mikologi Universitas Setia Budi yang telah banyak membantu proses isolasi dan identifikasi jamur xerofilik ini.

\section{DAFTAR PUSTAKA}

Gupta R.C. 2007. Plancental Toxicity. Science Direct. https://www.sciencedirect.com. Diakses 1 Februari 2019.

Irianto, K. 2013. Parasitologi Medis. Alfabeta, Bandung.
Liu C, Jiang X, Huang X, Chen J. 2010. A New Furanoid Toxin Produced By Curvularia lunata,the Causal Agent of Maize Curvularia Leaf Spot. Canadian Journal of Plant Pathology vol 31.

McKetta, J. 1995. Encyclopedia of Chemical Processing and Design. Marcel Dekker Inc.

Miskiyah, M., Winarti, C. dan Broto, W. 2015. Kontaminasi Mikotoksin pada Buah Segar dan Produk Olahannya serta Penanggulannya. Jakarta

Mizana, D.K., Sugarti. N. dan Amir, A. 2016. Identifikasi Pertumbuhan Jamur Aspergillus sp. Pada roti tawar yang dijual di kota Padang berdasarkan suhu dan lama penyimpanan. Jurnal Kesehatan Andalas 5(2).

Noveriza, R. 2008. Kontaminan Cendawan dan Mikotoksin pada tumbuhan Obat. Indonesian Agency for Agricultural and Development.

Pitt, J.I. \& Hocking A.D. 1985. Fungi and Food Spoilage. Academic Press. Sydney Orlando San Diego NewYork London Toronto Montreal Tokyo.

Rahayu, E.S. 2007. Mewaspadai Cemaran Mikotoksin. Food Review. Vol II (8)

Rukmini, I. 2009. Keanekaragaman Aspergillus Pada Berbagai Simplisia Jamu Tradisional. Jurnal Sains dan Matematika (JSM), 17 (2): 82 - 89.

Samson R.A., Hoekstra E.S. \& Oorschot C.A.N. 1984. Introduction To Food-borne Fungi. Centraalbureau Voor Schimelcultures.Institute of Royal Netherlands Academy of Arts And Science.

Santika, Wiryosoendjoyo, K. dan Pamungkas, G. 2017. Identifikasi Jamur Kontaminan yang bersifat Xerofilik pada lada bubuk. Biomedika. Vol.10 No. 02. September 2017.

Sukmawati, D., Wahyudi, P. Rahayu S., Moersilah, Handayani T., Rustam Y., dan Puspitasari S. 2018. Skrining Aspergillus sp. Penghasil Aflatoksin pada Jagung Pipilan di daerah Bekasi, Jawa Barat. Jurnal Biologi Al-Kauniyah. Vol 11. No. 2.

Wange. E.S.A., Suprapto D.N. dan Wirya, G.N.A.S. 2012. Isolasi dan Identifikasi Jamur Penghasil Mikotoksin pada Biji Kakao Kering yang dihasilkan di Flores. Journal of Agricultural Science and Agricultural. Vol 1 no. 01. 